\title{
Knowledge of the Use of Contraceptive among College of Health Sciences Students of Niger Delta University, Amassoma Bayelsa State, Nigeria
}

\author{
Oniso, Juliet Imawaigha1, Tawari Erebi Patricia ${ }^{2}$ \\ ${ }^{1}$ Department of Maternal and Child Health Nursing, Faculty of Nursing, College of Health Science, Niger Delta \\ University, Bayelsa State, Nigeria \\ ${ }^{2}$ Department of Chemical Pathology, Faculty of Basic Medical Sciences, College of Health Science, Niger Delta \\ University, Bayelsa State, Nigeria \\ Corresponding Author: Tawari Erebi Patricia
}

\begin{abstract}
Background: Unwanted pregnancy which results in unsafe abortion and sexually transmitted disease such as HIV/AIDS can be avoided by using different contraceptive methods. Information on knowledge, attitude and practice of contraceptives among students is particularly important because of unwanted pregnancies as well as an everyday increase in number of STI and HIV/AIDS. Tactlessly, in Nigeria significant proportion of students who engages in premarital sex, either lack basic knowledge of contraception, or are ignorant of practices of contraceptive. This study aimed at studying sexuality, knowledge of contraceptive in among students in the College of Health of Health Science, Niger Delta University, Amassoma.
\end{abstract}

Method: A descriptive cross-sectional study design was conducted among two hundred (200) students of the College of Health of Health Science, Niger Delta University aged 16-30 years. Data collection was carried out using both self-administered questionnaire

Results: The analysis of the data showed that majority of the students of the students in College of Health Science, Niger Delta University are about (84\%) sexually experience with most of the first sexual experiences occurring within the 16-20 years' age group. There is a high level of knowledge $(83 \%)$ of contraceptive available and where to get them but the level of contraceptive use is relatively lower $(61.5 \%)$ even for the sexually active notwithstanding their level of education. This could be attributed to the factors affecting contraceptive use identified by them which includes embarrassment to buy, lack of proper knowledge, fear of side effect, lack of money and disapproval by partners.

Conclusion: Majority of the respondents have a good knowledge on contraceptive. There is need to renew sex education campaigns in our primary, secondary and tertiary institutions as well as educating parents on the need to teach their wards about sex.

Key words: Knowledge, Contraceptive, Student, Bayelsa State

\section{INTRODUCTION}

Sexual and reproductive health is an important issue to every stakeholder in the global health sector particularly with regard to the youth and adolescents (Tien, 2011). Previous study indicates that adolescent/youth's sexual and reproductive health for most countries is in bad shape. (Attahir, et al., 2010) found out that the health risk faced by adolescent girls during pregnancy is very high, accounting for $15 \%$ of the Global Burden of Disease (GBD) for maternal conditions and $13 \%$ of all maternal deaths. The cause of this degenerating health condition of adolescent girls, according to Tien (2011), is lack of knowledge and access to contraception.

A study in Ghana (Eliason et al., 2014) reported that induced abortion with its 
related complications constitutes the most common outcomes of unintended pregnancies. About $12 \%$ of maternal deaths are attributed to induced abortions in Ghana. A maternal death among women without contraceptive use is 1.8 times higher as mentioned by (Hameed, et al.,2014). According to (Eliason, et al., 2014), up to $35 \%$ of maternal deaths and $13 \%$ of child mortalities could be prevented if birth intervals were at least 2 years.

Contraception is defined as the use of a contraceptive method to prevent pregnancy by interfering with ovulation, fertilization, and/or implantation (Csapo, et al., 2017). There are various methods of contraception which can be used by an adolescent for the prevention of pregnancy. The most appropriate method for birth control among sexually active adolescents depends on the following factors; age, the frequency of sexual activity, number of sexual partners, the desired number of children in the future, and family history of certain diseases. There is a disconnection between the levels of knowledge of adolescents on contraceptive usage. In Nigeria, Harrison (2013) observed that the high maternal mortality ratio (MMR) is attributed to youth's sexuality, this is characterized by low contraceptive usage by the youth, high incidence of illegal abortion amongst the youth, ignorance of contraception among the youth, and lack of sex education from parents and teachers. The situation in Nigeria is likely a reflection of the situation in the entire Africa. This study was conducted to assess the knowledge among students in College of Health Science, Niger Delta University, Bayelsa State.

\section{METHODOLOGY}

\section{Study Area}

The study was carried out at College of Health Science, Niger Delta University Wilberforce Island, Bayelsa state. The College of Health Science, Niger Delta University is located in Amassoma, Southern Ijaw Local Government Area,
Bayelsa state. Amassoma is made up of 22 compounds. Inhabitants are mainly Izons, other major ethnic groups' resident in the area includes Igbos, Hausas, Yoruba, Urhobos, Ibibios. Majority are Christians and few others in other faiths. Petty traders form the greatest bulk of the population with civil servants, farmers, fishermen/women as well as students cohabiting in the community respectively. College of Health Science is a tertiary institution; it is made up of various faculties and departments. The College is accessible by land and sea. It is composed of four major departments namely; Nursing, medicine and surgery, Medical laboratory science and Biochemistry.

\section{Sampling Technique}

The sampling technique to be used in this study is the simple random sampling technique. This was used to select two hundred (200) respondents out of the target population.

\section{Study Population}

The target population of the study were students of college of Health Science, Niger Delta University.

\section{Instrument for Data Collection}

A self-structured Questionnaire based on the use of contraceptive was randomly disturbed among the target population of students of College of Health Science, Niger Delta University.

\section{Validity of Instrument}

In other to determine the validity of the instrument, the questionnaire was prepared by the researcher and submitted to the research supervisor for necessary correction before administering to respondent.

\section{Reliability of Instrument}

In order to ensure the reliability of the instrument a test-retest method was used to test the reliability of the instrument. Their responses will be evaluated to ascertain the internal consistency of data obtained from the instrument. Question was reframed for 
clarity and relevance to the stated research objectives.

\section{Study Duration}

The study was carried out over a period of 4 weeks, consisting of time to be spent on obtaining approval, data collection, collation, analysis and report writing.

\section{Ethical Consideration}

Ethical approval for the conduct of the study was obtained from the Research and Ethics Committee of College of Health Science, Niger Delta University, before commencement.An informed consent will be obtained from the prospective respondent stating the purpose of the study and assurance of confidentiality. The respondent were made to understand that the study was for academic purpose and participation is voluntary and information provided will be treated with utmost confidentiality.

\section{RESULTS}

The total number of questionnaires administered was 200. Response rate was 100\%. 200 questionnaires were distributed and analysed. Tables were used to represent the results from the data analysis.

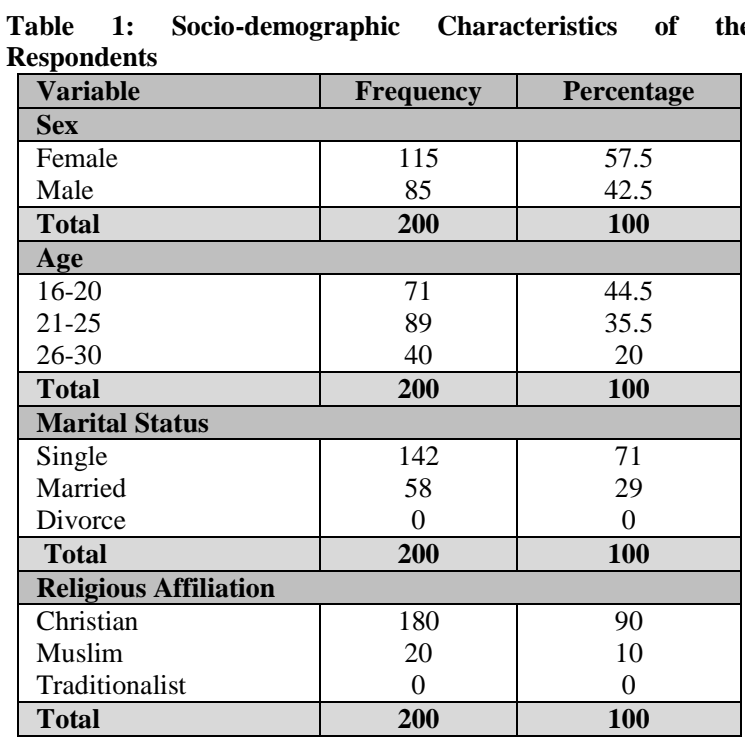

Table 1 showed the Sociodemographics Profile of the respondents. Majority of the respondents were female students $(57.5 \%)$. While the male respondents were $(42.5 \%)$ of the sample.
The highest proportions of respondents were aged between 16 and 20 years $(44.5 \%)$. Followed by those aged 21-25 (35.5\%) and then those aged 26-30years (20\%). The table also revealed that majority of the respondents are single (71.0\%) and married people were $29 \%$. No respondents in the sample were divorce. The distribution of respondents by religious affiliation showed that Christianity (90\%) was the dominant religion in the study location. This was followed by those who practiced Islamic Religion (10\%). There was no person found to practice African Traditional Religion.

Table 2 revealed that a sizable number of the respondents indicated that their mother has no formal education $(34.5 \%)$. This was followed by those who indicate their father has first degree and above $(35.5 \%)$. Respondents who indicated that their fathers completed secondary education were $(26.5 \%)$ of the samples. The lowest number of respondents' shows that their mother had first degree and above 13.5 percent.

Table 2: Distribution of respondents by parent's level of Education

\begin{tabular}{|l|c|c|c|c|}
\hline $\begin{array}{c}\text { Level of } \\
\text { relationship }\end{array}$ & Father & Percentage & Mother & Percentage \\
\hline $\begin{array}{l}\text { No formal } \\
\text { education }\end{array}$ & $\mathbf{3 6}$ & $\mathbf{1 8}$ & $\mathbf{6 9}$ & $\mathbf{3 4 . 5}$ \\
\hline $\begin{array}{l}\text { Completed } \\
\text { elementary }\end{array}$ & $\mathbf{4 0}$ & $\mathbf{2 0}$ & $\mathbf{5 0}$ & $\mathbf{2 5}$ \\
\hline $\begin{array}{l}\text { Completed } \\
\text { secondary }\end{array}$ & $\mathbf{5 3}$ & $\mathbf{2 6 . 5}$ & $\mathbf{5 1}$ & $\mathbf{2 5 . 5}$ \\
\hline $\begin{array}{l}\text { First degree } \\
\text { and above }\end{array}$ & $\mathbf{7 1}$ & $\mathbf{3 5 . 5}$ & $\mathbf{2 7}$ & $\mathbf{1 3 . 5}$ \\
\hline \multicolumn{1}{|c|}{ Total } & $\mathbf{2 0 0}$ & $\mathbf{1 0 0}$ & $\mathbf{2 0 0}$ & $\mathbf{1 0 0}$ \\
\hline
\end{tabular}

Table 3 shows that 28.5 percent of the respondents find it difficult to talk to their parents about things that are important to them. This was followed by 20.5 percent of respondents who very difficult discussing with them. The table also revealed that $(19.5 \%)$ each of the respondents find it very easy to talk to their parents. Besides, the table shows that (19\%) of the respondents indicated that they don't discuss with their parents at all about things that are important to them. Meanwhile, smaller proportion $(12.5 \%)$ of the respondents indicated that they relate with their parents at ease. 
Oniso, Juliet Imawaigha et.al. Knowledge of the use of contraceptive among College of Health Sciences students of Niger Delta University

Table 3: Youth Relationship with their Parents

\begin{tabular}{|c|c|c|}
\hline Level of relationship & Frequency & Percentage \\
\hline Very easy & 39 & 19.5 \\
\hline Easy & 25 & 12.5 \\
\hline Difficult & 57 & 28.5 \\
\hline Very difficult & 41 & 20.5 \\
\hline Not at all & 38 & 19 \\
\hline Total & 200 & 100 \\
\hline
\end{tabular}

Figure 1 shows that $(64 \%)$ of the respondents indicates that they never discuss sex-related matter with their parents. This was followed by (23\%) of those respondents who indicated that they occasionally discuss with their parents about sex-related issues. Meanwhile, the smaller portion 13 percent of the sample respondents indicated that they often discuss with their parents about sex related issues.

\section{Sex Related Matter with Parents}

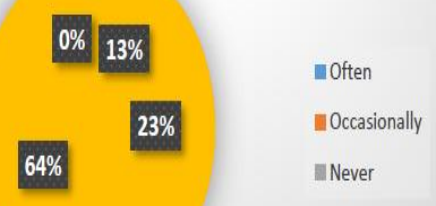

Figure 1: Distribution of Respondents by how often they discuss Sex-Related matters with parents

Table 4 showed that a higher proportion of respondents $(79 \%)$ have heard of any contraceptives while $21 \%$ of the respondents have not heard of any method of contraception.

Table 4: Distribution of Respondents by Knowledge of Contraception

\begin{tabular}{|c|c|c|}
\hline Knowledge of contraception & Frequency & Percentage \\
\hline Yes & 158 & 79 \\
\hline No & 42 & 21 \\
\hline Total & $\mathbf{2 0 0}$ & $\mathbf{1 0 0}$ \\
\hline
\end{tabular}

Table 5 showed that the three most frequently spontaneously named contraceptive methods the respondents indicated they know were condom, withdrawal, safe periods and pills (50\%, $39 \%$, and $19.5 \%$ respectively. This was followed by Injectable and pills method that students in College of Health Science, Niger Delta University have more knowledge of condoms, withdrawal and safe periods as a contraceptive method than any other methods

Table 5: Distribution of Respondents by type of Contraceptive Methods they know

\begin{tabular}{|l|c|c|}
\hline \multicolumn{1}{|c|}{ Contraceptive methods } & Frequency & Percentage \\
\hline Condom & 100 & 50 \\
\hline Pills & 27 & 13.5 \\
\hline Injectable & 12 & 6 \\
\hline Withdrawal & 78 & 39 \\
\hline Safe period & 39 & 19.5 \\
\hline \multicolumn{1}{|c|}{ Total } & $\mathbf{2 0 0}$ & $\mathbf{1 0 0}$ \\
\hline
\end{tabular}

Table 6 showed that friends, books/magazines, school teachers and mother were the three (3) most reported source of information about contraceptives $(37.5 \%, 21.0 \%$ and $15.5 \%)$. While only $(0 \%)$ of the total respondents knew about contraceptives through their father.

Table 6: Source of Knowledge of contraceptives

\begin{tabular}{|c|c|c|}
\hline Means of contraceptive knowledge & Frequency & Percentage \\
\hline School teacher & 42 & 21 \\
\hline Mother & 31 & 15.5 \\
\hline Father & 0 & 0 \\
\hline Brother & 9 & 4.5 \\
\hline Sister & 12 & 6 \\
\hline Friends & 75 & 37.5 \\
\hline Health professional & 12 & 6 \\
\hline Books/Magazine & 31 & 15.5 \\
\hline Total & 200 & 100 \\
\hline
\end{tabular}

Table 7 indicated that hundred and sixty-six (166) respondents know where to get contraceptives if they wanted. Twentythree (23) respondents identified that they don't know where to get it even if they wanted. Meanwhile about eleven of the respondents did not indicate.

Table 7: Distribution of respondents on whether they know where to get contraceptives

\begin{tabular}{|c|c|c|}
\hline $\begin{array}{c}\text { Level of knowledge on where } \\
\text { to get contraceptive }\end{array}$ & Frequency & Percentage \\
\hline Yes & 166 & 83 \\
\hline No & 23 & 11.5 \\
\hline No response & 11 & 5.5 \\
\hline Total & $\mathbf{2 0 0}$ & $\mathbf{1 0 0}$ \\
\hline
\end{tabular}

Figure 2, showed that majority of the respondents who said they know where to get contraceptives identified at least one source of contraceptives. Government health centre, private hospitals/clinic and patent shops $(35.0 \%, 26.0 \%$ and $23.0 \%)$ were three most frequently named sources of contraceptives. 


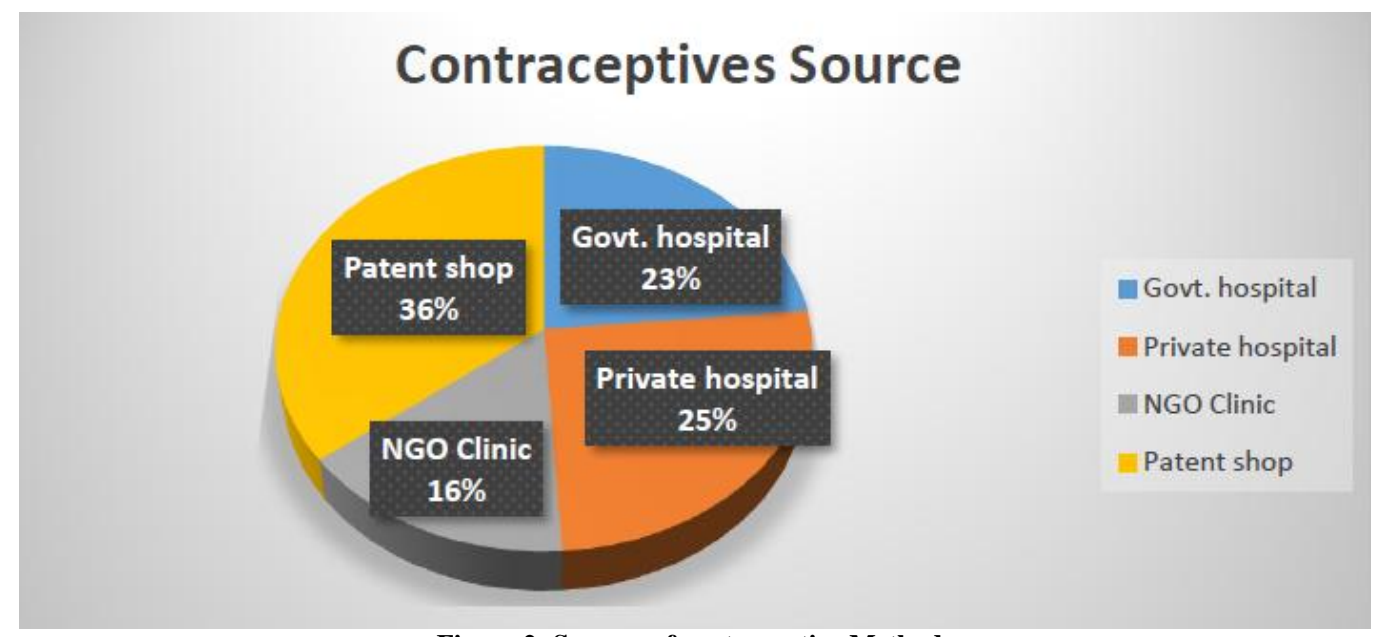

Figure 2: Sources of contraceptive Methods

Table 8 indicated that one hundred and seventy eight (178) respondents want to know more about contraceptives. This was followed by twenty two (22) respondents who indicated that they don't want to know more about contraceptives.

Table 8: Distribution of Respondents on if they will like to know more about contraceptives

\begin{tabular}{|c|c|c|}
\hline $\begin{array}{c}\text { Will you like to know more } \\
\text { about contraceptive methods }\end{array}$ & Frequency & Percentage \\
\hline Yes & 178 & 89 \\
\hline No & 22 & 11 \\
\hline Total & $\mathbf{2 0 0}$ & $\mathbf{1 0 0}$ \\
\hline
\end{tabular}

Table 9 showed that the majority of the respondents 55.5 percent stated that the purpose why the used a particular method was to prevent unwanted pregnancy, followed by 21.0 percent of those who said they used a particular method to prevent sexual transmitted diseases. Similarly, child spacing 4.5 percent and for medication 5.5 percent were other reasons.

Table 9: Distribution of Respondents for what purpose did they use a particular method

\begin{tabular}{|l|c|c|}
\hline $\begin{array}{l}\text { For what purpose did you use } \\
\text { contraceptive methods the last } \\
\text { time you had sexual intercourse? }\end{array}$ & $\begin{array}{c}\text { Frequency } \\
\mathbf{N = 2 0 0}\end{array}$ & $\begin{array}{c}\text { Percentage } \\
\mathbf{1 0 0 \%}\end{array}$ \\
\hline Prevent unwanted pregnancy & 111 & 55.5 \\
\hline Prevent sexually transmitted disease & 42 & 21 \\
\hline Child spacing & 9 & 4.5 \\
\hline Medication & 11 & 5.5 \\
\hline No response & 27 & 13.5 \\
\hline
\end{tabular}

\section{DISCUSSION}

Contraception is the use of a contraceptive method to prevent pregnancy by interfering with ovulation, fertilization, and/or implantation (Csapo, et al., 2017). It is one of the essential elements of youth reproductive health. It allows youth to determine the timing and the number of their children and empowers them to manage their lives with respect and dignity. Adolescent reproductive health is increasingly being recognized as one of the major determinant of human development. Among the essential development concern about contraception or prevention of unwanted early pregnancies considered to have a significant potential in improving the status of youth. Knowledge and use of contraceptives among youth showed very wide variation among region of sub-Saharan Africa than other regions of the world (Gadisa, 2014). The purpose of this study is to study the knowledge of contraceptives among students in College of Health Science, Niger Delta University. The respondents for the survey comprised, $57.5 \%$ females and $42.5 \%$ males. The age range of most of the respondents clustered between 16-25 years. The current levels of education of respondents are higher. However, majority of the respondents were Christians (90.0\%) and Moslems (10.0\%). This shows that populations of those who practices Christianity are quite high in Niger Delta University Amassoma.

Knowledge of contraceptive method is the first step toward accepting a method (Khan and Mishra, 2014). Subsequently knowledge is an important prerequisite in gaining access to contraceptives; it implies that knowledge of contraceptives level 
could be promising for better future use. With above $79 \%$ of total population of those who have knowledge of contraceptives from this study, it showed that the knowledge of contraceptives among students in College of Health Science, Niger Delta University is quite high. And with just $21 \%$ of those who lack knowledge of contraception. This finding is similar to previous reports from Ghana(Gadisa, 2014).

The desire of any student to use contraceptives depends on the knowledge and understanding of contraceptive methods. From the study through the questionnaire, many of the students had knowledge and are aware of contraception, and many were found to have been able to explain what contraceptives are meant for, and have cited contraceptives as methods or drugs used by women or men to prevent unplanned/unwanted pregnancies and spacing of children for their desired families. Some students also cited contraceptives as barrier methods which are used to prevent the infection of sexually transmitted diseases such as HIV/AIDS, gonorrhea, syphilis and among others. The increased in contraceptives knowledge of the students could possibly be attributed to the increased public health education usually disseminated through public health officers on radio, television, and friends, and these could have contributed to the increased contraceptives knowledge level of students who are sexually active.

The increase in contraceptives knowledge was equally found to be high as was reported by Ochako, et al., (2015) in Kenya in his study showed that there were high levels of contraceptive knowledge among adolescents although merely $43.0 \%$ were familiar with the use of a contraceptive method. Similar findings were reported in research of Gbagbo (2020) in Ghana which found out that there was high level of awareness among adolescents about contraceptives and where to obtain them. The results of their study showed that $21.0 \%$ of adolescents in some selected Senior High Schools with knowledge about contraceptives were users and $82.0 \%$ of them who were sexually active were nonusers.

Data from our research reported that the knowledge of students on contraceptive methods to include; condoms, Injection, emergency contraceptive pills, safe period and withdrawal with majority to have cited deep knowledge on the use of condoms (50\%), withdrawal (39\%), safe period $(19.5 \%)$ and pills (13.5\%). The increased knowledge on these methods could be attributed to the easy accessibility and availability of these methods in chemical shops/drug stores and pharmacies which could easily be purchased by these adolescents than going to the hospital, and also the current increased public education and TV advertisement on these emergency contraceptives pills in pregnancy prevention, and the use of condoms to the prevention of sexually transmitted diseases. This could also be related to (Longwe, et al., 2012) who reported that whether or not actual contraceptive use would increase over time, depends on the knowledge people have of family planning methods and their attitudes towards its associated services.

This research also revealed that some students had knowledge on the advantages of contraceptives as to the prevention of sexually transmitted diseases (STDs) (21\%), prevent unplanned pregnancy $(55.5 \%)$, help one to decide on the number of children he/she want $(4.5 \%)$, and for medication $(5.5 \%)$. These findings relate with the studies in Afolabi (2015), of Nigeria and cited the needs for adolescents to be better informed and educated on the various contraceptive methods.

\section{CONCLUSION AND RECOMMENDATION}

The level of knowledge of contraceptives methods was quite high among the youth in this study. Condom was the most known contraceptive method and teachers being the greatest source of knowledge of conceptive. 
We recommend that youth should be provided with basic knowledge of sexuality and contraception before the age they are likely to engage in sexual activities and effective channels of communication should be used to inform and educate youth using health professionals including, the author, trained teachers, and trained peer promoters and media.

\section{Acknowledgement: None}

\section{Conflict of Interest: None}

\section{Source of Funding: None}

\section{Ethical Approval: Approved}

\section{REFERENCES}

1. AbibaLongwe, Janine Huisman, Jeroen Smits. (2012). Effects of the Knowledge, acceptance and use of Contraceptives on household wealth in 26 African Countries.NICE Working Paper pp 12-109.

2. Afolabi BM, Ezedinachi E, Arikpo I, Ogunwale A, Ganiyu DF, Abu R, Ajibade A (2015). Knowledge, use and source of information on contraceptive methods among women in various stages of reproductive age in rural Lagos, Southwest Nigeria. Open Access journal of contraceptive Volume 6 Pages 65-75.

3. Attahir, A., Sufiyan, M. B., Abdulkadir, A \&Haruna, M. K. (2010). Knowledge, perception and practice of emergency contraception among female adolescent hawkers in Rigasa suburban community of Kaduna state, Nigeria. Journal of Family and Reproductive Health, 4 (1), 1-6.

4. Csapo, E., Goette, H. R., Green, J. R., In, C., Eidinow, E., Kindt, J., \& Osborne, R. (2017). Publications for Eric Csapo.

5. Eliason, S., Awoonor-Williams, J. K., Eliason, C., Novignon, J., Nonvignon, J., \&Aikins, M. (2014). Determinants of modern family planning use among women of reproductive age in the Nkwanta district of Ghana: a case-control study. Reproductive health, 11(1), 65.

6. Fred Yao Gbagbo (2020). "Contraceptive Use among Basic School Pupils in Ghana: A Case Study of a Municipality", International Journal of Pediatrics, vol. 2020, Article ID 7521096, 8 pages, 2020. https://doi.org/10.1155/2020/7521096

7. Gadisa, A. (2014). Implantable contraceptives for women: effectiveness, discontinuation rates, the return of fertility, and outcome of pregnancies, 65, 29-37.

8. Hameed, W., Azmat, S. K., Ali, M., Sheikh, M. I., Abbas, G., Temmerman, M., \&Avan, B. I. (2014). Women's empowerment and contraceptive use: the role of independent versus couples' decision-making, from a lower middle-income country perspective. PloS One, 9(8), e104633Tien, T. M. (2011). Impact of mass media exposure on knowledge and use of contraceptive among Vietnamese adolescents and youth. A thesis submitted to department of population and reproductive health, Mahildol University.

9. Harrison, k. A. (2013). The struggle to reduce maternal mortality in Nigeria. Okonofua, F.E (Ed), African journal of reproductive health, 13 (3), 9-20.

10. Khan, S. \& Mishra, V. (2014). Youth reproductive and sexual health. DHS comparative reports No 19. Calverton, USA, Macro International Inc.

11. Ochako, R., Mbondo, M., Aloo, S. (2015). Barriers to modern contraceptive methods uptake among young women Kenya: a qualitative study. BMC Public Health 15, 118. https://doi.org/10.1186/s12889-0151483-1

How to cite this article: Oniso, Juliet Imawaigha, Patricia TE. Knowledge of the use of contraceptive among College of Health Sciences students of Niger Delta University, Amassoma Bayelsa State, Nigeria. International Journal of Science \& Healthcare Research. 2021; 6(2): 459-465. DOI: https://doi.org/ 10.52403/ijshr.20210446 